\title{
SITE SPECIFIC NUTRIENT MANAGEMENT FOR MAIZE (ZEA MAYS L) IN SOUTHERN DRY ZONE OF KARNATAKA
}

\author{
S. B. YOGANANDA ${ }^{1}$, T. SHESHADRI ${ }^{2}$, P. THIMME GOWDA ${ }^{3}$, SHRUTHI, G. K. ${ }^{4}$ \& SHRUTHI, M. K. ${ }^{5}$ \\ ${ }^{1,3,4}$ Department of Agronomy, Zonal Agricultural Research Station, V. C. Farm, Mandya, Karnataka, India \\ ${ }^{2,5}$ Department of Agronomy, University of Agricultural Sciences, GKVK, Bangalore, India,
}

\begin{abstract}
A field experiment was conducted during kharif seasons, of 2013, 2014 and 2015 in five locations i.e., Nandinathapura, Chikkahonnur, Charapura, Beguru and Chowthi villages of Periyapatna taluks, to study the effect of Site Specific Nutrient Management, for Maize. Yield responses to fertilizer application, was in the order of $N>K>P$ ranging in an average, from 22.63 to $26.64 q$ /ha for $N$, from 10.68-17.89 q/ha for $K$, and from 5.42 to 9.60 for $P$. The average increase in the grain yield of maize in omission plots, is in the order of PK $(59.4 q / h a)<N P(70.2 q / h a)<N K(76.9$ q/ha $)$. This shows that, $N$ is the most limiting nutrient, affecting maize yield. Across the locations, attainable yields measured in NPK and SSNM, plots on an average ranged from 84.2 to 91.0 q/ha while yields in the FFP plot, on average ranged from 68.0 to 73.6 q/ha. This indicates that ICM, mainly seed treatment with fungicide, herbicide for weed control and $\mathrm{ZnSO}_{4}$ application, had positive effect on the crop growth and yield. Grain yield in SSNM plot was 5.5 to $7.7 q /$ ha more than the NPK plots, although these two treatments are statistically at par with each other.
\end{abstract}

KEYWORDS: Maize, Site Specific Nutrient Management \& Agronomic Efficiencies

Received: Jun 05, 2017;Accepted: Jul 09, 2017; Published: Jul 18, 2017; Paper Id.: IJASRAUG201735

\section{INTRODUCTION}

Maize (Zea mays L.) is one of the most important crops next, only to wheat and rice in terms of total production in the world. Maize is grown throughout the world, under a wide range of climatic conditions. The major producers of the maize in the world are USA followed by China, Brazil, Mexico, Argentina and India. In the world, maize is grown in the area of $140 \mathrm{mha}$, with a production of $800 \mathrm{mt}$. In India, during 2014-15, maize is grown in an area of $9.43 \mathrm{mha}$, with a production of $24.35 \mathrm{mt}$, with an average productivity of $2583 \mathrm{~kg} \mathrm{ha}^{-1}$. In Karnataka, maize is grown on an area of $1.38 \mathrm{mha}$, with a production of $3.98 \mathrm{mt}$, and productivity of $2883 \mathrm{~kg} \mathrm{ha}^{-1}$ (Anon, 2015).

Periyapatana taluk of Mysore District, is one of the major maize growing areas in Southern Dry Zone of Karnataka. Out of the 83121 hectares of geographical area, and 42980 hectares under cultivable area, of which 15628 hectares are under maize cultivation. The average yield in this area is 30-35 q/ ha, which is higher than the national and state average. However, it is possible to achieve yield potential of $80-90 \mathrm{q} / \mathrm{ha}$. The grain yield of maize is mainly depends on variety, growing season, soil fertility, rainfall and crop management practices, implemented by the farmers. Main production constraints are depletion of soil fertility, due to continuous mono cropping, emergence of pest and diseases, weeds, drought etc.

The general fertilizer recommendation for maize in Southern Dry Zone of Karnataka was 150:75:40 kg N, $\mathrm{P}_{2} \mathrm{O}_{5}$ and $\mathrm{K}_{2} \mathrm{O} \mathrm{ha}^{-1}$, but most of the farmers apply urea, up to $200-225 \mathrm{~kg} / \mathrm{ha}$, without $\mathrm{K}_{2} \mathrm{O}$ and $\mathrm{P}_{2} \mathrm{O}_{5}$. This general fertilizer recommendation and current farmer's fertilizer practice are not based on the nutrient requirements of the 
maize crop and the nutrients available in the soil. The application of fertilizers does not meet the crop's need. Application of adequate quantities of nutrients play an important role, in increasing the maize productivity and production, but those nutrients should be given in a balanced way, based on the plant requirement. According to Ferguson et. al. (2002), site specific management of soil fertility inputs, is an attractive and intuitive approach, to increasing fertilizer use efficiency.

To increase the productivity of maize, through site-specific nutrient management on-farm experiments were conducted in the sandy loam soils of several villages, of Periyapatna taluk, during the rainy season in 2013, 2014 and 2015.

\section{MATERIALS AND METHODS}

Study Area

On-farm experiments were conducted during the rainy season of 2013, 2014 and 2015, in five locations i.e., Nandinathapura, Chikkahonnur, Charapura, Beguru and Chowthi villages of Periyapatna taluk. The soil of all the villages was sandy loam in texture with organic carbon content, of $0.43 \%$.

\section{Experimental Setup}

The experimental setup followed a standard procedure, at all villages and included nutrient omission plots (PK, NK, NP), to estimate indigenous nutrient supplies, an NPK plot to measure yield response to fertilizer application, and a farmers fertilizers practice (FFP) plot, in each farmer's field. Plot wise soil samples were taken, for initial soil analysis and based on the soil test results SSNM treatment was included. Each of the above treatments was paralleled by a plot, with improved crop management practices (ICM) i.e., seed treatment with fungicide, use of atrazine for weed control and application of $\mathrm{ZnSO}_{4} @ 25 \mathrm{~kg} / \mathrm{ha}$. Locations/ villages are used as replicates. Individual plot sizes were $5 \mathrm{~m} \mathrm{X} 5 \mathrm{~m}$, for the treatments of PK, PK + ICM, NK, NK + ICM, NP, NP + ICM, NPK and NPK + ICM; and 10 m X $10 \mathrm{~m}$ for SSNM, SSNM + ICM, FFP, FFP + ICM. Fertilizer rates in the omission plots, NPK, SSNM and FFP treatments are shown in Table 1.

Urea was used as the N-Source in plots with N application (NK, NP, NPK and SSNM plots). Basal N (50\%) was applied at the time of sowing, with top dressing at knee height stage (25\%) and teaseling stage (25\%). The plots with $\mathrm{P}$ application (NP, PK, NPK and SSNM plots), the P source was SSP. The source of K in PK, NK, NPK and SSNM was $\mathrm{KCl}$. Both $\mathrm{P}$ and $\mathrm{K}$ were applied as basal dose at the time of sowing. Farmer's fertilizer applications were splits twice for $\mathrm{N}$ (Urea) at 15 and 30 DAS. While, $\mathrm{P}$ (SSP) and $\mathrm{K}(\mathrm{KCl})$ applied at 15 DAS Before sowing composite soil samples were taken at 0-30 $\mathrm{cm}$ depth from each location. Nutrients and fractions analyzed were particle size, soil organic carbon, $\mathrm{pH}$, EC, soil N, $\mathrm{P}_{2} \mathrm{O}_{5}$, and $\mathrm{K}_{2} \mathrm{O}$. Management practices implemented were based on the best recommendations and technologies developed by University of Agricultural Sciences, Bangalore. Maize hybrid sown in the trial was Nityashree in all the locations. All treatments received full control from weeds, pests and diseases.

\section{Data Analysis}

Grain yield was measured at final harvest grain yield data were analyzed using standard statistical procedures. Yield response to fertilizer NPK application were obtained from the differences between the yield in NPK (+/- ICM) and the relevant omission plot (0-N, 0-P, 0-K) (Cassaman et al., 1998) with the formula, $\mathrm{AY}=\mathrm{Y}_{\mathrm{NPK}}-\mathrm{Y}_{0 \mathrm{x}}$

Where, $\mathrm{AY}=\mathrm{Yield}(\mathrm{q} / \mathrm{ha})$ response to $\mathrm{X}$ fertilizers; $\mathrm{Y}_{\mathrm{NPK}}=$ Yield $(\mathrm{q} / \mathrm{ha})$ in plot that received fertilizer nutrient; and $\mathrm{Y}_{0 \mathrm{x}}=\mathrm{Yield}(\mathrm{q} / \mathrm{ha})$ in plot without $\mathrm{X}$ fertilizer.

Agronomic efficiency was measured as the amount of crop yield increase per unit nutrient applied (Cassaman et 
al., 1998) with the formula;

$\mathrm{AE}_{\mathrm{X}}=\left(\mathrm{Y}_{\mathrm{NPK}-} \mathrm{Y}_{0 \mathrm{x}}\right) / \mathrm{F}_{\mathrm{X}}$

Where, $\mathrm{AE}_{\mathrm{X}}=$ Agronomic efficiency of Nutrient $\mathrm{X}(\mathrm{kg} / \mathrm{ha}) ; \mathrm{Y}_{\mathrm{NPK}}=$ Yield $(\mathrm{kg} / \mathrm{ha})$ in plot that received fertilizer nutrient; $Y_{0 x}=$ Yield $(\mathrm{kg} / \mathrm{ha})$ in plot without $\mathrm{X}$ fertilizer; and $\mathrm{F}_{\mathrm{X}}=$ Rate $(\mathrm{kg} / \mathrm{ha})$ of nutrient $\mathrm{X}$ fertilizer applied.

\section{RESULTS AND DISCUSSIONS}

\section{Soil Properties}

The soil of experimental site was red sandy loam comprising maximum sand (77.0\%) with bulk density of $1.35 \mathrm{~g}$ $\mathrm{cc}^{-1}$. The soil $\mathrm{pH}$ was neutral in reaction (6.85). The soil was low in organic carbon $(0.37 \%)$, low in available nitrogen $(222$ $\mathrm{kg} / \mathrm{ha})$, medium in phosphorus $(17.2 \mathrm{~kg} / \mathrm{ha})$ and medium in potassium $(130 \mathrm{~kg} / \mathrm{ha})$. This soil available nutrient data indicated that there is an ample of scope in implementing the site specific nutrient management practices in this area based on grid wise soil test results.

\section{Yield Responses to Fertilizer Application}

Yield responses to fertilizer application was in the order of $\mathrm{N}>\mathrm{K}>\mathrm{P}$ ranging an average from 22.63 to $26.64 \mathrm{q} / \mathrm{ha}$ for $\mathrm{N}$, from 10.68-17.89 q/ha for K, and from 5.42 to 9.60 for P (Fig. 1)

The magnitude of yield response to applied fertilizer is depended on the indigenous nutrient supplying capacity of the soils and environmental conditions during the crop growing seasons. Yield response to NPK fertilizers were higher in first year where, growing conditions were more favorable, as indicated by the higher yields obtained in the NPK and SSNM treatment plots as compared to other omission plots. Yield response to fertilizers application is very variable among the locations and seasons, thus, nutrient management strategies that handle such variability are clearly required.

\section{Agronomic Efficiencies}

Agronomic efficiency (AE) is one of the several indicators of nutrient use efficiency. It is expressed as the yield increase per unit fertilizer applied ( $\mathrm{kg}$ grain per $\mathrm{kg}$ fertilizer). It is a measure of the ability of a plant to transform the amount of fertilizer applied in to economic yield. Fig. 2 indicates the agronomic efficiency for N, P and K measured from the NPK treatment plots. On an average, AE ranged from 15 to $18 \mathrm{~kg}$ grain per $\mathrm{kg} \mathrm{N}$ applied, from 7 to $13 \mathrm{~kg}$ grain per $\mathrm{kg}$ $\mathrm{P}$ applied, and from 32-45 kg grain per kg K applied (Fig. 2). Julie Mae Pasuquin et al. (2010) also reported improved agronomic efficiency of $\mathrm{N}$ fertilizers by $53 \%$ compared to the farmers practice in South East Asia.

\section{Yield Comparison}

The grain yield of maize was varied significantly due to nutrient management practices (Table 2). The average increase in the grain yield of maize in omission plots is in the order of PK $(59.4 \mathrm{q} / \mathrm{ha})<\mathrm{NP}(70.2 \mathrm{q} / \mathrm{ha})<\mathrm{NK}(76.9 \mathrm{q} / \mathrm{ha})$. This shows that $\mathrm{N}$ is the most limiting nutrient affecting maize yield, whereas $\mathrm{P}$ and $\mathrm{K}$ supply are equally limiting factors.

Across the locations, attainable yields measured in NPK and SSNM plots on an average ranged from 84.2 to 91.0 $\mathrm{q} /$ ha while yields in the FFP plot on average ranged from 68.0 to $73.6 \mathrm{q} / \mathrm{ha}$. This clearly shows that a substantial yield gap of about 16 to $17 \mathrm{q} / \mathrm{ha}$ exists between farmer's actual yield and what is attainable with optimal crop and nutrient management. Differences in grain yield among the seasons are mainly attributed to seasonal fluctuations in climate and other environmental factors. 
In general, ICM treatments resulted in higher yields compared to plots without ICM. This indicates that ICM, mainly seed treatment with fungicide, herbicide for weed control and $\mathrm{ZnSO}_{4}$ application, had positive effect on the crop growth and yield.

Grain yield in SSNM plot was 5.5 to $7.7 \mathrm{q} /$ ha more than the NPK plots, although these two treatments are statistically at par with each other. This clearly indicated that, site specific nutrient management is the best option for enhancing the maize yield and reducing the cost of cultivation. The similar results are also reported by Julie Mae Pasuquin et al. (2010) wherein, compared to farmers practice, SSNM improved the maize grain yield by about 0.9 to $1.3 \mathrm{Mg} / \mathrm{ha}$.

Table 1: Fertilizer Rate and Application in the Treatments

\begin{tabular}{|l|c|c|c|c|}
\hline \multirow{2}{*}{ Treatment } & \multicolumn{5}{|c|}{ Quantity of Fertilizer (kg/ha) } \\
\cline { 2 - 5 } & $\mathbf{N}$ & $\mathbf{P}_{\mathbf{2}} \mathbf{O}_{\mathbf{5}}$ & $\mathbf{K}_{\mathbf{2}} \mathbf{O}$ & $\mathbf{Z n S O}_{\mathbf{4}}$ \\
\hline NP & 150 & 75 & - & - \\
\hline NP + ICM & 150 & 75 & - & 25 \\
\hline PK & - & 75 & 40 & - \\
\hline PK + ICM & - & 75 & 40 & 25 \\
\hline NK & 150 & - & 40 & - \\
\hline NK + ICM & 150 & - & 40 & 25 \\
\hline NPK & 150 & 75 & 40 & - \\
\hline NPK + ICM & 150 & 75 & 40 & 25 \\
\hline SSNM & 188 & 75 & 40 & - \\
\hline SSNM + ICM & 188 & 75 & 40 & 25 \\
\hline FFP & 200 & 50 & 25 & - \\
\hline FFP + ICM & 200 & 50 & 25 & 25 \\
\hline
\end{tabular}

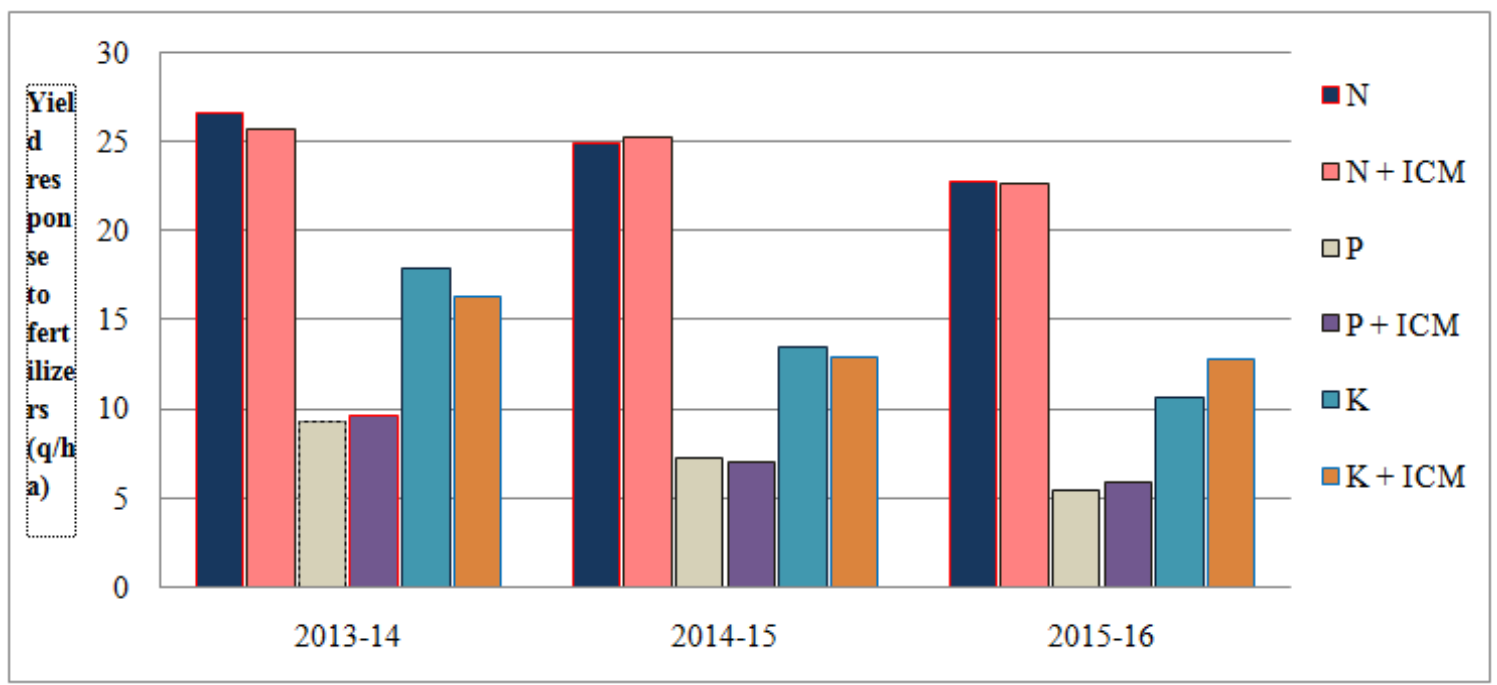

Figure 1: Yield Response to N, P and K Fertilizers and Applications Based on NPK

Table 2: Maize Grain Yield as Influenced by Different Nutrient Management Practices

\begin{tabular}{|l|c|c|c|}
\hline \multirow{2}{*}{ Treatment } & \multicolumn{3}{|c|}{ Maize Grain Yield (q/ha) } \\
\cline { 2 - 4 } & $\mathbf{2 0 1 3 - 1 4}$ & $\mathbf{2 0 1 4 - 1 5}$ & $\mathbf{2 0 1 5 - 1 6}$ \\
\hline NP & 67.13 & 70.22 & 73.12 \\
\hline NP + ICM & 72.07 & 73.68 & 74.84 \\
\hline PK & 58.38 & 58.83 & 61.06 \\
\hline PK + ICM & 62.72 & 61.28 & 64.96 \\
\hline NK & 75.78 & 76.43 & 78.38 \\
\hline NK + ICM & 78.78 & 79.54 & 81.71 \\
\hline
\end{tabular}




\begin{tabular}{|l|c|c|c|}
\hline NPK & 85.02 & 83.73 & 83.81 \\
\hline NPK + ICM & 88.38 & 86.56 & 87.59 \\
\hline SSNM & 90.53 & 91.48 & 90.94 \\
\hline SSNM + ICM & 95.71 & 96.63 & 96.52 \\
\hline FFP & 68.04 & 69.28 & 73.60 \\
\hline FFP + ICM & 72.94 & 72.23 & 75.84 \\
\hline S.E m. $\mathbf{\pm}$ & 3.25 & 4.12 & 4.46 \\
\hline CD@5\% & $\mathbf{9 . 2 6}$ & $\mathbf{1 1 . 7 3}$ & $\mathbf{1 2 . 7 1}$ \\
\hline CV\% & $\mathbf{9 . 5 2}$ & $\mathbf{1 2 . 0 1}$ & $\mathbf{1 2 . 7 0}$ \\
\hline
\end{tabular}

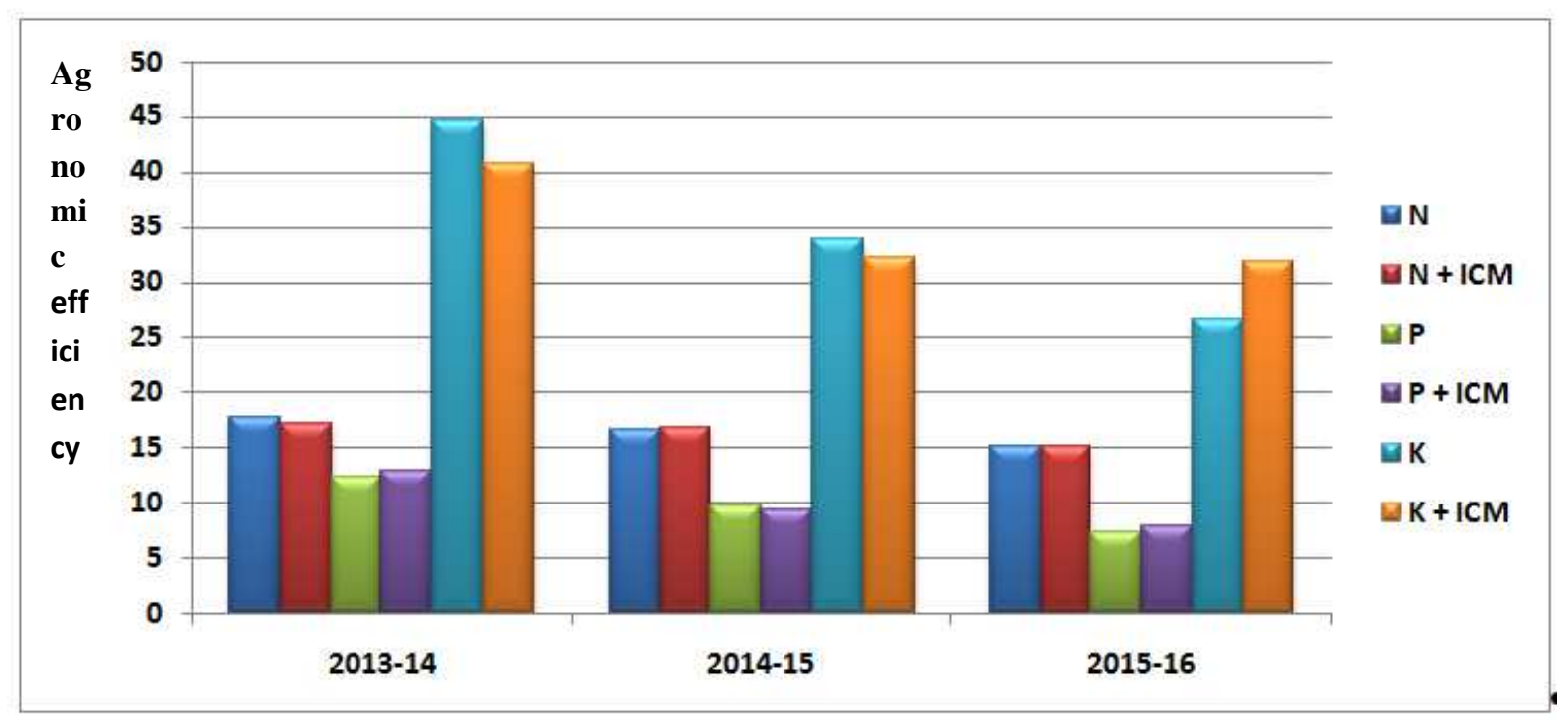

Figure 2: Agronomic Efficiencies N, P, and K Based on NPK and SSNM Treatments

\section{CONCLUSIONS}

The soils of maize growing area in Periyapatana Taluk generally low in organic carbon and Nitrogen content, thus the addition of organic matter and nitrogenous fertilizers are required to achieve higher maize grain yield.

There are great opportunities for maize farmers of Pertiyapatna taluk, to increase their productivity and profitability with SSNM. Yield increase of about 16-17 q/ha over farmer's fertilizers practice can be achieved with SSNM practices based on grid wise analyzed soil data.

\section{REFERENCES}

1. Anonymous, 2015. Annual Report (2014-15), Directorate of Economics and Statistics, GOI.

2. Cassman, K. G., Peng, S., Olk, D. C., Ladha, J. K., Reichardt, W., Dobermann, A. \& Singh, U. (1998). Opportunities for increased nitrogen use efficiency from improved resource management in irrigated rice system. Field Crop Research, 56, 7278.

3. Ferguson, R. B., Hergert, G. W., Schepers, J. S., Gotway, C. A., Cahoon, J. E. \& Peterson, T. A. (2002). Site specific nitrogen management of irrigated maize: Yield and soil residual nitrate effect. Soil Science Society of American Journal, 64, 190-195.

4. Julie Mae Pasuquin, Christian Witt \& Mirasol Pampolino. (2010). A new site-specific nutrient management approaches for maize in the favorable tropical environments of Southeast Asia. In: 19th World Congress of Soil Science, Soil Solutions for a Changing World, 1 - 6 August 2010, Brisbane, Australia. P. 4-7. 

